\title{
Allergic contact dermatitis caused by laurel leaf oil
}

\section{Susana Brás, Pedro Mendes-Bastos, Cristina Amaro and Jorge Cardoso}

Department of Dermatology and Venereology, Hospital de Curry Cabral - Centro Hospitalar de Lisboa Central, 1069-166 Lisboa, Portugal

doi:10.1111/cod.12377

Key words: allergic contact dermatitis; cosmetics; laurel oil; Laurus nobilis; sesquiterpene lactones.

Correspondence: Susana Brás, Hospital de Curry Cabral - Centro Hospitalar de Lisboa Central, Rua da Beneficência, No. 8, 1069-166 Lisboa, Portugal. Tel: +351 916969143. E-mail: bras.susana@gmail.com

Conflict of interests: All of the authors declare that they have no conflicts of interests.
Laurus nobilis is a common plant in the Mediterranean area, and is used in several cosmetic products and remedies due to its claimed analgesic, antioxidant and anti-inflammatory effects (1). Laurel oil contains cineol, pinene, citral, terpineol, and several sesquiterpene lactones (2). Contact allergy to laurel has been mostly 

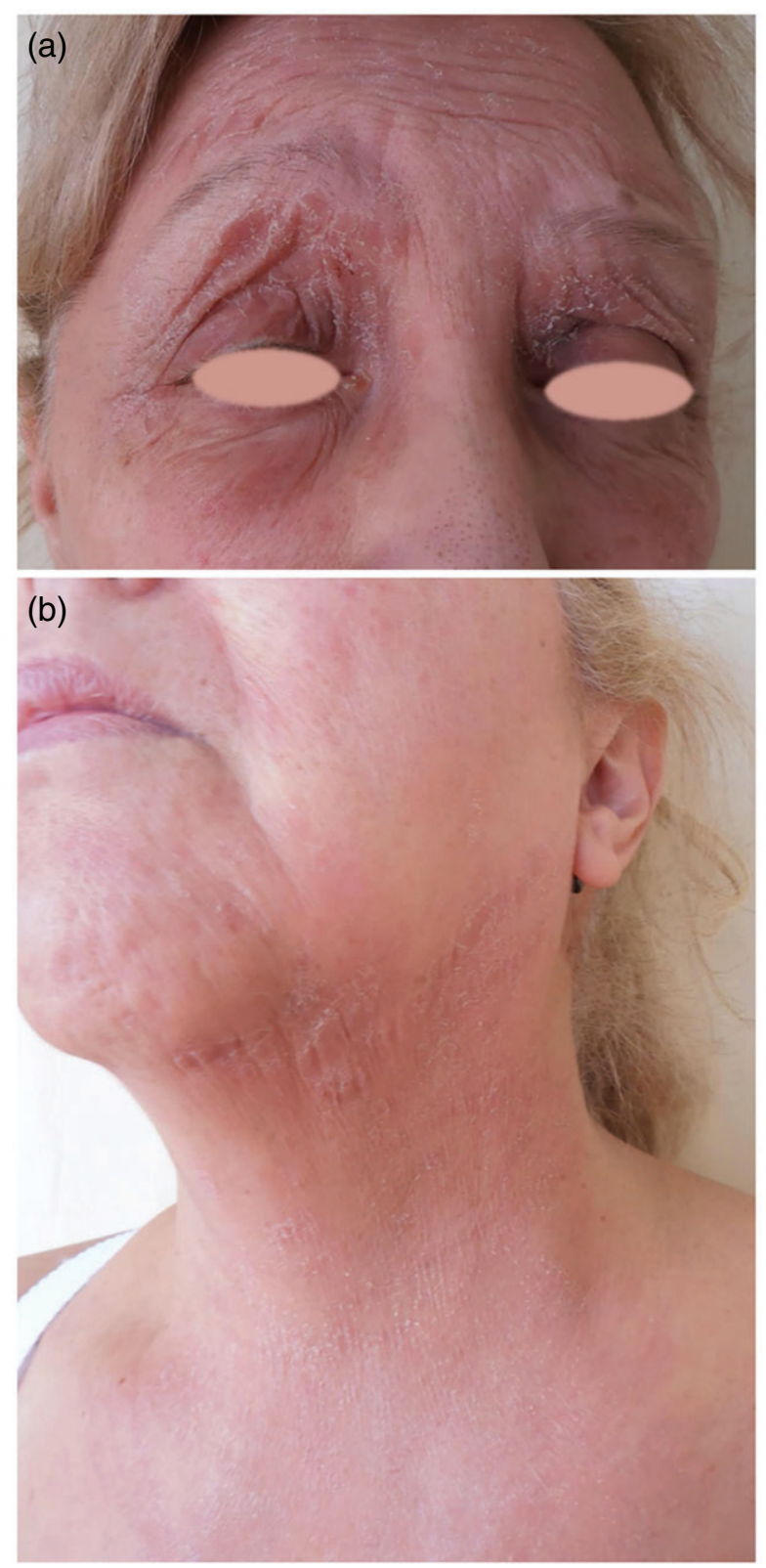

Fig. 1. Eczematous lesions around the eyes (a) and on the neck (b).

reported in aromatherapists and patients who apply herbal oils for joint pain (3-6).

\section{Case Report}

A 62-year-old white woman presented with a 10-day history of itching eczematous lesions around her eyes, cheeks, and neck (Fig. 1), where she had applied a cosmetic oil, Gamila Secret ${ }^{\mathbb{R}}$, for the previous 3 weeks. This oil contained, according to its label, several plant extracts: Vitis vinifera seed oil, Prunos amygdalus dulcis oil, Simmondsia chinensis seed oil, Lavandula angustifolia oil, Nigella sativa seed oil, Olea europaea fruit oil, Persea gratíssima oil, L. nobilis leaf oil, Pistacia vera seed oil, and Inula helenium extract. The patient was treated with an oral antihistamine and hydrocortisone cream, and the lesions subsequently healed.

One month later, patch testing was performed with Finn Chambers ${ }^{\circledR}$, according to the ICDRG criteria, with the Portuguese baseline series, cosmetic and excipient series, individual components of fragrance mixes I and II, plant series, linalool and limonene hydroperoxides, the patient's own products, including the Gamila Secret ${ }^{\circledR}$ oil 'as is', and laurel leaf oil and lavender essential oil, the only two components available. The patient had positive reactions at day (D) 2 and D4 to Compositae mix II $5 \%$ pet. (Chemotechnique ${ }^{\circledR}$, Vellinge, Sweden) $(+)$, to sesquiterpene lactone mix $0.1 \%$ pet (Chemotechnique ${ }^{\circledR}$, Vellinge, Sweden) $(++)$, to the Gamila Secret ${ }^{\circledR}$ oil 'as is' $(++)$, and to laurel leaf oil $2 \%$ pet. $\left(\right.$ Bial $^{\circledR}$, Coronado, Portugal) (+) (Fig. 2).

\section{Discussion}

We report a case of allergic contact dermatitis caused by laurel oil following the application of a cosmetic oil containing L. nobilis leaf oil. Contact allergy to laurel oil is rare, and only a few cases have been described from the skin application of laurel oil skin as a massage oil (4-6). However, we cannot exclude the possibility of contact allergy to other allergens contained in the cosmetic oil, as not all of the ingredients were available for patch testing.

Positive reactions to L. nobilis, Compositae mix and sesquiterpene lactone mix suggest the diagnosis of sesquiterpene lactone-induced allergic contact dermatitis. The role of sesquiterpene lactones in patients sensitized to laurel oil has been discussed in some studies $(7,8)$. The sesquiterpene lactones are characterized by the presence of a $\gamma$-butyrolactone ring with an exocyclic $\alpha$-methylene group. Numerous different molecules with this structure are present in plants of the families Compositae (Asteraceae), Magnoliaceae, Winteraceae, Jubulaceae, and Lauraceae (9). Contact allergy is directed primarily against the $\alpha$-methylene group. Cross-reactions among plants belonging to the Compositae family, plants of the genera Frullania (Jubulacea family) and Laurus (Lauracea family) and various members of the family Magnoliacea, such as Michelia lanuginosa, have been described in the literature $(7,9,10)$. Patients allergic to laurel oil should therefore avoid products containing extracts, and contact with plants, known to contain sesquiterpene lactones. 

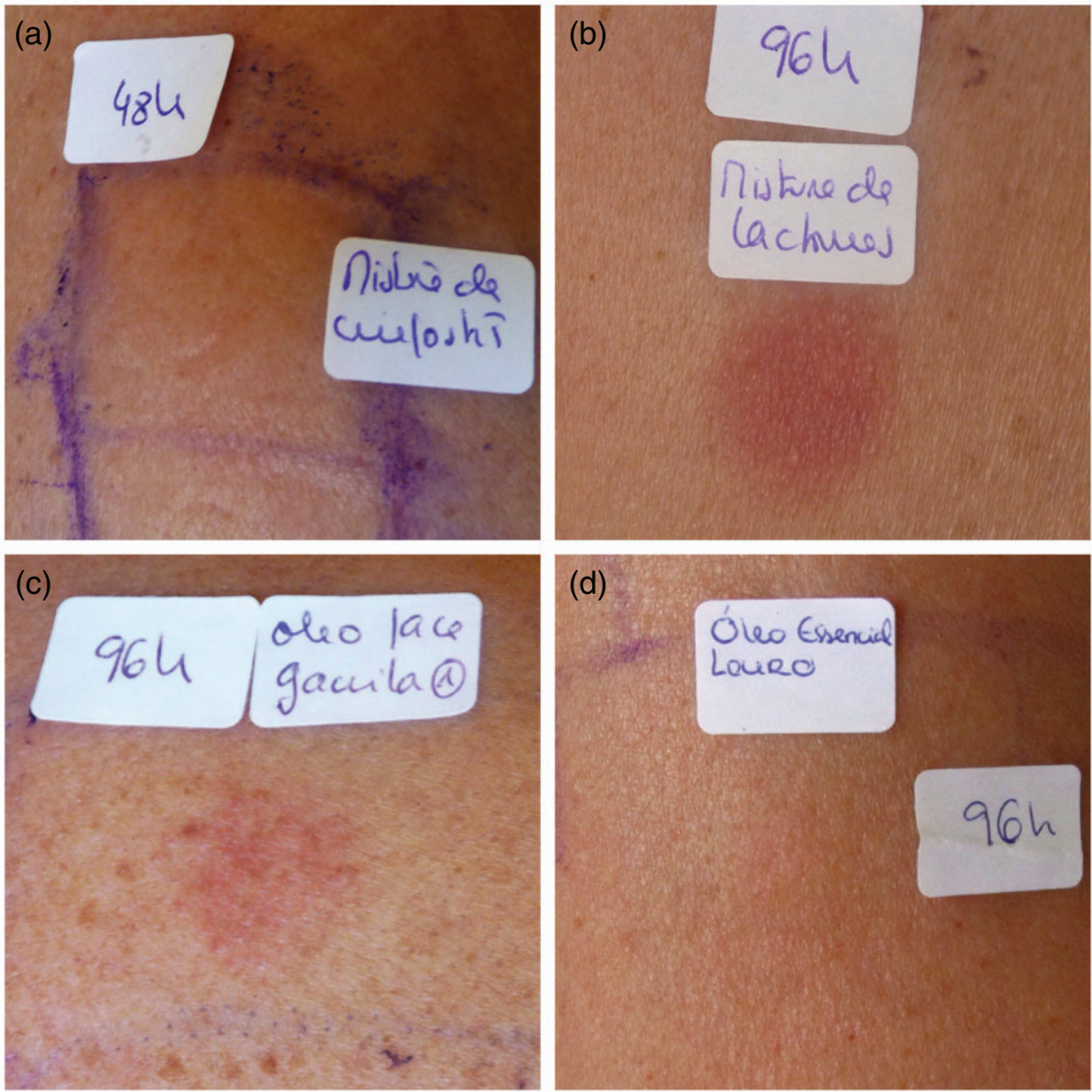

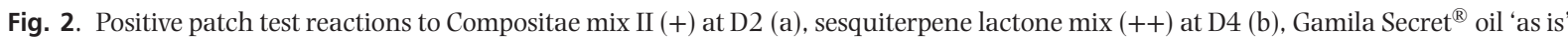
$(++)$ at D4 (c), and laurel leaf oil (+) at D4 (d).

\section{References}

1 Ramos C, Teixeira B, Batista I et al. Antioxidant and antibacterial activity of essential oil and extracts of bay laurel Laurus nobilis Linnaeus (Lauraceae) from Portugal. Nat Prod Res 2012: 26: 518-529.

2 Dooms-Goossens A, Dubelloy R, Degreef H. Contact and systemic contact-type dermatitis to spices. Dermatol Clin 1990: 8: 89-93.

3 Keane FM, Smith HR, White IR, Rycroft RJ. Occupational allergic contact dermatitis in 2 aromatherapists. Contact Dermatitis 2000: 43: 49-51
4 Adisen E. Allergic contact dermatitis from Laurus nobilis oil induced by massage. Contact Dermatitis 2007: 56: 360-361.

5 Ozden M G, Oztaş P, Oztaş M O, Onder M. Allergic contact dermatitis from Laurus nobilis (laurel) oil. Contact Dermatitis 2001: 45: 178 .

6 Athanasiadis G I, Pfab F, Klein A, Braun-Falco M, Ring J, Ollert M. Erythema multiforme due to contact with laurel oil. Contact Dermatitis 2007: 57: 116-118.

7 Le Coz C, Ducombs G. Plants and plant products. In: Contact Dermatitis, 4th edition, Frosch P, Menné M, Lepoittevin J (eds): Berlin, Germany, Springer, 2006: pp. $722-724$.
8 Stampf J, Schlewer G, Ducombs G, Foussereau J, Benezra C. Allergic contact dermatitis due to sesquiterpene lactones. Br J Dermatol 1978: 99: 163-169.

9 Kanerva L, Estlander T, Alanko K, Jolanki R. Patch test sensitization to Compositae mix, sesquiterpene-lactone mix, Compositae extracts, laurel leaf, Chlorophorin, Mansonone A, and dimethoxydalbergione. Am J Contact Dermat 2001: 12: 18-24.

10 Foussereau J, Muller J C, Benezra C. Contact allergy to Frullania and Laurus Nobilis: cross-sensitization and chemical structure of the allergens. Contact Dermatitis 1975: 1: 223-230. 